\title{
cmaJOPEN
}

\section{Characteristics of frequent emergency department users in British Columbia, Canada: a retrospective analysis}

\author{
Jessica Moe MD MSc, Fiona O’Sullivan PhD, Margaret J. McGregor MD MHSc, \\ Michael J. Schull MD MSc, Kathryn Dong MD MSc, Brian R. Holroyd MD MBA, Eric Grafstein MD, \\ Corinne M. Hohl MD MHSc, Johanna Trimble, Kimberlyn M. McGrail PhD
}

Abstract

Background: Frequent emergency department users disproportionately account for rising health care costs. We aimed to characterize frequent emergency department users in British Columbia, Canada.

Methods: We performed a retrospective analysis using health administrative databases. We included patients aged 18 years or more with at least 1 emergency department visit from 2012/13 to 2015/16, linked to hospital, physician billing, prescription and mortality data. We used annual emergency department visits made by the top $10 \%$ of patients to define frequent users ( $\geq 3$ visits/year).

Results: Over the study period, $13.8 \%-15.3 \%$ of patients seen in emergency departments were frequent users. We identified 205136 frequent users among 1196353 emergency department visitors. Frequent users made 40.3\% of total visits in 2015/16. From $2012 / 13$ to $2015 / 16$, their visit rates per 100000 BC population showed a relative increase of $21.8 \%$, versus $13.1 \%$ among all emergency department patients. Only $1.8 \%$ were frequent users in all study years. Mental illness accounted for $8.2 \%$ of visits among those less than 60 years of age, and circulatory or respiratory diagnoses for $13.3 \%$ of visits among those aged 60 or more. In $2015 / 16$, frequent users were older and had lower household incomes than nonfrequent users; the sex distribution was similar. Frequent users had more prescriptions (median 9, interquartile range [IQR] 5-14 v. 1, IQR 1-3), primary care visits (median 15, IQR 9-27 v. 7, IQR 4-12) and hospital admissions (median 2, IQR 1-3 v. 1, IQR 1-1), and higher 1-year mortality (10.2\% v. 3.5\%) than nonfrequent users.

Interpretation: Emergency department use by frequent users increased in BC between 2012/13 and 2015/16; these patients were heterogenous, had high mortality and rarely remained frequent users over multiple years. Our results suggest that interventions must account for heterogeneity and address triggers of frequent use episodes.

anadians spent $\$ 7068$ per capita on health care in 2019, with emergency department expenses accounting for a higher proportion of costs than in previous years. ${ }^{1,2}$ High users of health care services are a national priority for cost containment. ${ }^{3,4}$ Specifically, frequent users of emergency departments account for only $4.5 \%-8 \%$ of emergency department patients, yet make $21 \%-30 \%$ of visits., They are high and costly users of other health care services. ${ }^{7-9}$ In addition, they make higher-acuity visits, and are admitted and die more often than nonfrequent users. ${ }^{10-14}$

Effective solutions to improve patient care and decrease costly health care use require a detailed understanding of frequent emergency department users. Most characterizations have been conducted at the institutional level and in other countries, ${ }^{15-19}$ and previous Canadian provincial analyses are cross-sectional rather than longitudinal., ${ }^{9,20,21}$ Population-level trends and transitions into frequent use remain unexplored.

Interventions described to date (e.g., case management, care plans) may decrease emergency department visits by frequent users ${ }^{16,18,22}$ but have not been studied rigorously in Canada. Sustainable solutions require a nuanced understanding of the nature (not just quantity) of frequent users' interactions with the health care system. For instance, more than $93 \%$ of frequent users are attached to primary care, although the continuity and appropriateness of these relationships have not been explored., ${ }^{923-27}$ Liaising frequent users with primary care providers at discharge has mixed effects on emergency department use. ${ }^{28,29}$ It is unknown whether improving the quality of primary care relationships can redirect frequent users toward nonacute care and improve outcomes. We hypothesized that frequent users might experience less primary care continuity.

Our objective was to characterize frequent emergency department users in British Columbia using a longitudinal, linked provincial database of demographic, clinical and health care use data.

Competing interests: Kathryn Dong reports personal fees from Alberta Health Services and the College of Physicians and Surgeons of Alberta, outside the submitted work. No other competing interests were declared.

This article has been peer reviewed.

Correspondence to: Jessica Moe, jessica.moe@ubc.ca

CMAJ Open 2021. DOI:10.9778/cmajo.20200168 


\section{Methods}

\section{Design, setting and participants}

This was a retrospective analysis of administrative databases capturing patients who visited an emergency department in BC between fiscal years 2012/13 and 2015/16. The study cohort comprised patients aged 18 years or more who made at least 1 emergency department visit, identified based on classification within the National Ambulatory Care Reporting System (NACRS) (Appendix 1, Supplemental Figure S1, available at www.cmajopen.ca/content/9/1/E134/suppl/DC1). ${ }^{30}$ Twenty emergency departments contributed to NACRS in 2012/13, and 29 from 2013/14 to 2015/16. These institutions accounted for an estimated $74 \%$ of total emergency department visits in $\mathrm{BC}$ in $2015 / 16{ }^{31}$

\section{Data sources}

Our study cohort (from NACRS) was linked to data on hospital admissions (Canadian Institute for Health Information Discharge Abstract Database), ${ }^{32}$ physician billing (Medical Services Plan), ${ }^{33}$ prescription medications (PharmaNet) ${ }^{34}$ and mortality (BC Vital Statistics Agency). ${ }^{35}$ Population Data BC (PopData) houses and links databases using patient health number, age, sex and postal code. PopData is a multiuniversity resource supporting linkage and access to individuallevel, deidentified data for research. It was established in 2009 but originated in the 1980s as the BC Linked Health Data Set, funded by the provincial Ministry of Health. PopData performs validation and employs rigorous, standardized linkage procedures, using a combination of deterministic and probabilistic approaches. ${ }^{36,37}$

\section{Variables and definitions}

\section{Frequent and nonfrequent users}

We defined frequent users as patients within our cohort in the top $10 \%$ of emergency department users in each fiscal year and nonfrequent users as patients in the bottom $90 \%$ of emergency department users, consistent with the Canadian Institute for Health Information definition. ${ }^{38} \mathrm{We}$ chose the institute's definition to facilitate future comparisons with a top $10 \%$ cohort of emergency department users in other Canadian provinces. In our data set, the top $10 \%$ of emergency department users corresponded to 3 or more visits annually.

To determine visit counts, we first attempted to identify and remove scheduled revisits. Clinicians on our team determined that most scheduled revisits in $\mathrm{BC}$ are for intravenous antibiotic treatment for cellulitis. We therefore developed an algorithm to identify emergency department visit strings occurring within 48 hours of one another with an initial diagnosis of cellulitis. To verify the accuracy of our approach, we examined diagnoses associated with 48-hour repeat emergency department visits in 2012/13. Cellulitis was the most common specified diagnosis (12.1\%), followed by abdominal pain (4.0\%), follow-up examination (3.0\%) and other medical care $(2.3 \%)$.

\section{Demographic characteristics}

Sex, age, rural/urban residence and average neighbourhood income adjusted for household size ${ }^{39}$ were available for frequent and nonfrequent users in our database. We obtained population estimates from the Government of BC..$^{40}$

\section{Acute care}

We obtained characteristics of emergency department visits (ambulance arrival, triage level, diagnoses, disposition) from NACRS.

We defined visit acuity using the Canadian Triage and Acuity Scale, a national tool that allows emergency departments to prioritize care. ${ }^{41}$ Its 5 acuity levels range from life- or limb-threatening presentations requiring immediate care (level 1) to patients whose condition is stable in whom delayed assessment is not expected to cause deterioration (level 5). ${ }^{42}$ The scale has high interrelater reliability and excellent predictive validity for resource use, costs and admission. ${ }^{43-45}$

We obtained hospital admission dates and diagnoses from the Discharge Abstract Database.

\section{Physician visits and majority source of care}

We used the general practitioner specialty code to identify primary care providers and visits from the Medical Services Plan.

We counted number of visits to primary care physicians and number of unique primary care physicians seen. To describe primary care continuity, we calculated a "majority source of care" variable indicating whether the patient received 3 or more services in 1 year, and $50 \%$ or more of services from 1 primary care physician. ${ }^{46,47}$

\section{Mortality}

We obtained death dates and causes from the BC Vital Statistics Agency, and examined mortality by sex, age and age group.

\section{Diagnostic categories}

Emergency department, hospital and mortality diagnoses were recorded within NACRS, the Discharge Abstract Database and the BC Vital Statistics Agency database using the International Statistical Classification of Diseases and Related Health Problems, 10th Revision (ICD-10). We summarized diagnoses by the 22 ICD-10 chapters. ${ }^{48}$

\section{Prescription medications}

Using the provincial PharmaNet database, we defined unique medications as those with distinct generic drug names, consistent with previous literature. ${ }^{49} \mathrm{We}$ summarized unique medication counts by age group and American Hospital Formulary Service first-tier categories. The American Hospital Formulary Service is a widely used classification system that groups drugs with similar pharmacologic, therapeutic or chemical characteristics in a tiered hierarchy. ${ }^{50}$

\section{Statistical analysis}

We characterized frequent and nonfrequent user groups for each fiscal year, using all data sources available, and reported descriptive statistics. We analyzed data from all available 
emergency department visits from all institutions reporting to NACRS to characterize our cohort. With the exception of 1 component of our analysis in which we calculated the relative percent change in emergency department visits overall and for frequent users' visits over the study period (expressed as a rate per annual BC population), we limited our analysis to a selection of 20 emergency departments that consistently reported to NACRS in all years to account for changes in reporting. We performed analyses using $\mathrm{R}$ ( $\mathrm{R}$ Foundation for Statistical Computing).

\section{Ethics approval}

The University of British Columbia Clinical Research Ethics Board approved this study (H18-00287).

\section{Results}

Over the study period, $13.8 \%-15.3 \%$ of emergency department patients were frequent users (Table 1). We identified 205136 frequent users among 1196353 emergency department patients. At the 20 institutions that consistently reported to NACRS over the study period, the visit rate per 100000 of the BC population among frequent users increased from 6066 in $2012 / 13$ to 7387 in $2015 / 16$, a relative increase of $21.8 \%$. In comparison, the rate of visits per 100000 population made by all patients at these institutions increased from 16051 to 18146 over the study period, a relative increase of $13.0 \%$.

Frequent users made a median of 4 (interquartile range [IQR] 3-5) emergency department visits in each study year. The proportion of visits attributable to mental illness increased from $4.7 \%(13344 / 284016)$ in $2012 / 13$ to $6.0 \%$ (28 391/472 603) in 2015/16. In 2015/16, 23 153/283 403 visits $(8.2 \%)$ among frequent users aged $18-59$ years were related to mental illness; of these, $9431(40.7 \%)$ were related to psychoactive substance use, $4046(17.5 \%)$ to psychosis, $4042(17.5 \%)$ to anxiety, and $2877(12.4 \%)$ to mood disorders. Of all prescriptions provided to frequent users within this age group, $1238082(17.3 \%)$ were for an opioid medication (Appendix 1, Supplemental Table S1). Circulatory and respiratory diagnoses accounted for 25 207/189 200 visits (13.3\%) among frequent users aged 60 or more (Appendix 1, Supplemental Table S2).

A minority of frequent users were frequent users in the subsequent year $(20.2 \%, 21.4 \%$ and $24.7 \%$ in $2012 / 13,2013 / 14$ and $2014 / 15$, respectively), $21.9 \%$ of patients were frequent users in multiple consecutive or nonconsecutive years, and $1.8 \%$ of patients were frequent users in all study years in which they were alive $(1.9 \%$ when examining only those alive during the entire study period). Almost one-third (30.8\%) of nonfrequent users were nonfrequent users in multiple years.

\section{Comparison of frequent users and nonfrequent users}

We report frequent and nonfrequent users' characteristics in 2015/16, our most recent year of data (Table 2). Frequent users $(n=102811)$ were older than nonfrequent users $(n=$ 569740 ) (median age 54, IQR 35-73 yr v. 50, IQR 33-66 yr) and disproportionately represented the 2 lowest neighbourhood income quintiles (48.3\% v. $42.0 \%)$. The sex distribution was similar (53.1\% and $51.8 \%$ female, respectively).

Frequent users arrived more commonly by ambulance (26.1\% v. $18.8 \%)$, made higher acuity visits and were admitted to hospital more often $(18.8 \%$ v. $14.0 \%)$ than nonfrequent users. Their most common discharge diagnoses related to a broad category of symptoms, including abdominal pain, chest pain, headache and fever. Mental disorders accounted for $6.0 \%$ of frequent users' visits. Frequent users had a greater median number of admissions than nonfrequent users $(2, \mathrm{IQR}$ 1-3 v. 1, IQR 1-1). The most common admission diagnoses were mental disorders for frequent users (15.2\%) and circulatory diseases for nonfrequent users (17.3\%).

Frequent users made a median of 15 (IQR 9-27) primary care visits to a median of 6 (IQR 4-9) primary care physicians. In contrast, nonfrequent users made a median of 7 (IQR 4-12) primary care visits to a median of 3 (IQR 2-5) primary care physicians. The proportions of frequent users and nonfrequent users who had a physician who provided the majority of their care were similar (43.9\% v. $45.5 \%)$. A total of 777 frequent users $(0.8 \%)$ made no primary care visits, and 2610 (2.5\%) made $1-2$ visits. The corresponding values for the nonfrequent users were 19839 (3.5\%) and 82269 (14.4\%). Frequent users had more prescription medications than nonfrequent users (median 9, IQR 5-14 v. 1, IQR 1-3).

Frequent users had a higher mortality rate within 1 year of their last emergency department visit than nonfrequent users $(10.2 \%$ v. $3.5 \%)$.

\section{Interpretation}

Our analyses indicate that emergency department visits increased each year in BC from 2012/13 to 2015/16 and that visits by frequent users of the emergency department rose disproportionately: we found a relative increase of $21.8 \%$ in frequent users' visits over the study period, compared to $13.0 \%$ for all patients. Frequent use tended to be transient; only $1.8 \%$ of patients were frequent users in all study years in which they were alive $(1.9 \%$ for those who were alive during all study years). Frequent users were heterogenous, with differing diagnoses among age subgroups (e.g., mental health among younger patients, and circulatory and respiratory among older patients).

Frequent users were high users of other health care services. They were admitted to hospital more often, visited more primary care physicians and made more primary care visits than nonfrequent users. We hypothesized that frequent users might experience less primary care continuity, consistent with prior research; ${ }^{51,52}$ however, our results were not able to confirm this hypothesis. Finally, frequent users experienced poor health outcomes. We observed high relative numbers of prescription medications (which could indicate inappropriate prescribing or many comorbidities, or both), ${ }^{49}$ high comparative admissions and a 1-year mortality rate nearly 3 times greater than that for nonfrequent users $(10.2 \%$ v. $3.5 \%)$. 


\begin{tabular}{|c|c|c|c|c|}
\hline Characteristic & $2012 / 13$ & $2013 / 14$ & $2014 / 15$ & $2015 / 16$ \\
\hline Total no. of patients & 452427 & 559902 & 643000 & 672551 \\
\hline Total no. of visits & 757562 & 942298 & 1112400 & 1171839 \\
\hline No. of frequent users ( $\%$ of all patients) & $62552(13.8)$ & $78984(14.1)$ & $97120(15.1)$ & $102811(15.3)$ \\
\hline No. of visits by frequent users & 284016 & 355742 & 442854 & 472603 \\
\hline Total no. of visits/100 000 population & 16362 & 20019 & 23290 & 24116 \\
\hline $\begin{array}{l}\text { No. of visits by frequent } \\
\text { users } / 100000 \text { population }\end{array}$ & 6134 & 7558 & 9272 & 9726 \\
\hline \multicolumn{5}{|l|}{$\%$ of total visits attributable to frequent visits } \\
\hline Top $10 \%$ users & 37.5 & 37.7 & 39.8 & 40.3 \\
\hline Top 5\% users & 25.5 & 25.4 & 27.2 & 27.7 \\
\hline Top $1 \%$ users & 8.6 & 8.2 & 8.9 & 9.5 \\
\hline No. of visits, median (IQR) & $4(3-5)$ & $4(3-5)$ & $4(3-5)$ & $4(3-5)$ \\
\hline \multicolumn{5}{|l|}{ Frequent emergency department users } \\
\hline \multicolumn{5}{|l|}{ Patient characteristics } \\
\hline \multicolumn{5}{|l|}{ Sex, no. (\%) of patients } \\
\hline Female & $32881(52.6)$ & $41551(52.6)$ & $51639(53.2)$ & $54585(53.1)$ \\
\hline Male & $29655(47.4)$ & $37420(47.4)$ & $45461(46.8)$ & $48210(46.9)$ \\
\hline Unknown & $16(0.02)$ & $13(0.02)$ & $20(0.02)$ & $16(0.02)$ \\
\hline \multicolumn{5}{|l|}{ Age category, yr, no. (\%) of patients } \\
\hline $18-29$ & $11252(18.0)$ & $13928(17.6)$ & $17140(17.6)$ & $17962(17.5)$ \\
\hline $30-39$ & $8766(14.0)$ & $11192(14.2)$ & 13468 (13.9) & $14320(13.9)$ \\
\hline $40-49$ & $8651(13.8)$ & $10640(13.5)$ & $12583(13.0)$ & $13088(12.7$ \\
\hline $50-59$ & $9130(14.6)$ & $11571(14.6)$ & $13853(14.3)$ & $14899(14.5)$ \\
\hline $60-69$ & $7879(12.6)$ & $10026(12.7)$ & $12581(13.0)$ & $13447(13.1)$ \\
\hline$\geq 70$ & $16874(27.0)$ & $21627(27.4)$ & $27495(28.3)$ & $29095(28.3)$ \\
\hline Age at year end, median (IQR), yr & $53(35-72)$ & $53(34-72)$ & $54(35-73)$ & $54(35-73)$ \\
\hline \multicolumn{5}{|l|}{ Visit characteristics } \\
\hline \multicolumn{5}{|l|}{ Top 5 diagnostic categories (ICD-10 chapter) } \\
\hline $\begin{array}{l}\text { Symptoms, signs, and abnormal } \\
\text { clinical and laboratory findings (XVIII) }\end{array}$ & $45000(15.8)$ & $63544(17.9)$ & $82383(18.6)$ & $87247(18.5)$ \\
\hline $\begin{array}{l}\text { Injury, poisoning and certain other } \\
\text { consequences of external causes } \\
\text { (XIX) }\end{array}$ & $28709(10.1)$ & $38390(10.8)$ & $49566(11.2)$ & $53119(11.2)$ \\
\hline Mental and behavioural disorders (V) & $13344(4.7)$ & $19103(5.4)$ & $24023(5.4)$ & $28391(6.0)$ \\
\hline Disease of genitourinary system (XIV) & $12402(4.4)$ & $16595(4.7)$ & $22199(5.0)$ & $23235(4.9)$ \\
\hline $\begin{array}{l}\text { Diseases of musculoskeletal system } \\
\text { and connective tissue (XIII) }\end{array}$ & $11376(4.0)$ & $15753(4.4)$ & $20283(4.6)$ & $22025(4.7)$ \\
\hline Missing & $105512(37.2)$ & $105922(29.8)$ & $116761(26.4)$ & $122105(25.8)$ \\
\hline
\end{tabular}

There is a potential for improved efficiency from interventions addressing the extensive use of health care services by frequent users. We observed income disparity between frequent and nonfrequent users, which policy interventions could target.

Our findings corroborate those of previous studies showing that frequent users are heterogenous, high users of primary care and other services, and have prevalent mental health and chronic illness, and increased mortality. ${ }^{7,12,13,14,16,19,53,54}$ The evanescent nature of frequent emergency department use may indicate a naturally self-limiting state triggered by acute crisis. We suspect that many patients move into and out of the frequent user state as acute crises resolve. For clinicians who 


\section{Research}

\begin{tabular}{|c|c|c|}
\hline \multirow[b]{2}{*}{ Characteristic } & \multicolumn{2}{|c|}{ No. (\%) of patients or visits* } \\
\hline & $\begin{array}{l}\text { Nonfrequent users } \\
n=569740\end{array}$ & $\begin{array}{c}\text { Frequent users } \\
n=102811\end{array}$ \\
\hline \multicolumn{3}{|l|}{ Patients } \\
\hline \multicolumn{3}{|l|}{ Sex } \\
\hline Female & $295385(51.8)$ & $54585(53.1)$ \\
\hline Male & $274283(48.1)$ & $48210(46.9)$ \\
\hline Unknown & $72(0.01)$ & $16(0.02)$ \\
\hline Age, median (IQR), yr & $50(33-66)$ & $54(35-73)$ \\
\hline \multicolumn{3}{|l|}{ Neighbourhood income quintile } \\
\hline Q1 (lowest) & $122615(21.5)$ & $28100(27.3)$ \\
\hline Q2 & $116585(20.5)$ & $21598(21.0)$ \\
\hline Q3 & $111426(19.6)$ & $19294(18.8)$ \\
\hline Q4 & $110531(19.4)$ & $17199(16.7)$ \\
\hline Q5 (highest) & $98238(17.2)$ & $14699(14.3)$ \\
\hline Unknown & $5901(1.0)$ & $1329(1.3)$ \\
\hline Missing & $4444(0.8)$ & $592(0.6)$ \\
\hline \multicolumn{3}{|l|}{ Residence } \\
\hline Rural & $31623(5.6)$ & $4642(4.6)$ \\
\hline Urban & $533673(93.7)$ & 97577 (94.9) \\
\hline Missing & $4444(0.8)$ & $592(0.6)$ \\
\hline No. of visits, median (IQR) & $1(1-1)$ & $4(3-5)$ \\
\hline \multicolumn{3}{|l|}{ Mortality } \\
\hline $\begin{array}{l}\text { No. of deaths within } 1 \mathrm{yr} \text { of last } \\
\text { emergency department visit }\end{array}$ & $19836(3.5)$ & $10475(10.2)$ \\
\hline \multicolumn{3}{|l|}{ Sex } \\
\hline Male & $10380(52.3)$ & $4822(46.0)$ \\
\hline Female & $9441(47.6)$ & $5650(53.9)$ \\
\hline Unknown & $15(<0.00)$ & $3(<0.00)$ \\
\hline Age at death, median (IQR), yr & $81(69-89)$ & $78(66-87)$ \\
\hline \multicolumn{3}{|l|}{ Visits } \\
\hline Total no. of visits & 699236 & 472603 \\
\hline \multicolumn{3}{|l|}{ Transportation method } \\
\hline Air ambulance & $356(0.1)$ & $86(0.02)$ \\
\hline $\begin{array}{l}\text { Combination of air and ground } \\
\text { ambulance }\end{array}$ & $226(0.05)$ & $79(0.02)$ \\
\hline Ground ambulance & $131335(18.8)$ & $123419(26.1)$ \\
\hline No ambulance & $567319(81.1)$ & $349019(73.9)$ \\
\hline \multicolumn{3}{|c|}{$\begin{array}{l}\text { Triage level (Canadian Triage and Acuity } \\
\text { Scale) }\end{array}$} \\
\hline 1 (Resuscitation) & $5014(0.7)$ & $3357(0.7)$ \\
\hline 2 (Emergent) & $114723(16.4)$ & $83750(17.7)$ \\
\hline 3 (Urgent) & $337639(48.3)$ & $239910(50.8)$ \\
\hline 4 (Less urgent) & $220680(31.6)$ & $121871(25.8)$ \\
\hline 5 (Nonurgent) & $19113(2.7)$ & $22326(4.7)$ \\
\hline Unknown & $2067(0.3)$ & $1389(0.3)$ \\
\hline
\end{tabular}




\begin{tabular}{|c|c|c|}
\hline \multirow[b]{2}{*}{ Characteristic } & \multicolumn{2}{|c|}{ No. (\%) of patients or visits* } \\
\hline & $\begin{array}{c}\text { Nonfrequent users } \\
n=569740\end{array}$ & $\begin{array}{l}\text { Frequent users } \\
n=102811\end{array}$ \\
\hline $\begin{array}{l}\text { Top } 5 \text { diagnostic categories (ICD-10 } \\
\text { chapter) }\end{array}$ & $\begin{array}{l}129292(18.5) \\
\text { Injury, poisoning and certain other } \\
\text { consequences of external causes } \\
(\mathrm{XIX)}\end{array}$ & $\begin{array}{c}87247 \text { (18.5) } \\
\text { Symptoms, signs, and abnormal } \\
\text { clinical and laboratory findings } \\
\text { (XVIII) }\end{array}$ \\
\hline & $\begin{array}{c}122264 \text { (17.5) } \\
\text { Symptoms, signs, and abnormal } \\
\text { clinical and laboratory findings (XVIII) }\end{array}$ & $\begin{array}{l}122264(17.5) \\
\text { Injury, poisoning and certain other } \\
\text { consequences of external causes } \\
(\mathrm{XIX)}\end{array}$ \\
\hline & $\begin{array}{c}29882(4.3) \\
\text { Diseases of digestive system (XI) }\end{array}$ & $\begin{array}{l}28391(6.0) \\
\text { Mental and behavioural disorders (V) }\end{array}$ \\
\hline & $\begin{array}{c}29804(4.3) \\
\text { Diseases of respiratory system (X) }\end{array}$ & $\begin{array}{c}22548(4.8) \\
\text { Diseases of respiratory system }(X)\end{array}$ \\
\hline & $\begin{array}{c}24808 \text { (3.5) } \\
\text { Diseases of circulatory system (IX) }\end{array}$ & $\begin{array}{l}21803(4.6) \\
\text { Diseases of digestive system (XI) }\end{array}$ \\
\hline Missing & $185520(26.5)$ & $122105(25.8)$ \\
\hline \multicolumn{3}{|l|}{ Discharge disposition } \\
\hline $\begin{array}{l}\text { Discharged to place of residence (home } \\
\text { or institution) }\end{array}$ & $598572(85.6)$ & $380633(80.5)$ \\
\hline Admitted or transferred & $98039(14.0)$ & $89107(18.8)$ \\
\hline Left before completion of treatment & $2024(0.3)$ & $2684(0.6)$ \\
\hline Died & $601(0.09)$ & $179(0.04)$ \\
\hline No. of drug prescriptions, median (IQR) & $1(1-3)$ & $9(5-14)$ \\
\hline \multicolumn{3}{|l|}{ Hospital admission } \\
\hline $\begin{array}{l}\text { No. of admissions per person, median } \\
\text { (IQR) }\end{array}$ & $1(1-1)$ & $2(1-3)$ \\
\hline \multirow[t]{5}{*}{$\begin{array}{l}\text { Top } 5 \text { discharge diagnostic categories } \\
\text { (ICD-10 chapter) }\end{array}$} & $\begin{array}{c}19953 \text { (17.3) } \\
\text { Diseases of circulatory system (IX) }\end{array}$ & $\begin{array}{l}14661 \text { (15.2) } \\
\text { Mental and behavioural disorders (V) }\end{array}$ \\
\hline & $\begin{array}{c}17255 \text { (14.9) } \\
\text { Injury, poisoning (XIX) }\end{array}$ & $\begin{array}{c}13221 \text { (13.7) } \\
\text { Diseases of circulatory system (IX) }\end{array}$ \\
\hline & $\begin{array}{c}15527 \text { (13.4) } \\
\text { Diseases of digestive system (XI) }\end{array}$ & $\begin{array}{c}11273 \text { (11.7) } \\
\text { Diseases of digestive system (XI) }\end{array}$ \\
\hline & $\begin{array}{c}10774(9.3) \\
\text { Mental and behavioural disorders (V) }\end{array}$ & $\begin{array}{c}10074(10.5) \\
\text { Diseases of respiratory system }(\mathrm{X})\end{array}$ \\
\hline & $\begin{array}{c}10110(8.7) \\
\text { Diseases of respiratory system (X) }\end{array}$ & $\begin{array}{l}9656(10.0) \\
\text { Symptoms and abnormal clinical and } \\
\text { laboratory findings (XVIII) }\end{array}$ \\
\hline \multicolumn{3}{|l|}{ Physician billing } \\
\hline $\begin{array}{l}\text { No. of primary care physicians visits, } \\
\text { median (IQR) }\end{array}$ & $7(4-12)$ & $15(9-27)$ \\
\hline $\begin{array}{l}\text { No. of individual primary care physicians } \\
\text { visited, median (IQR) }\end{array}$ & $3(2-5)$ & $6(4-9)$ \\
\hline Majority source of care & $259203(45.5)$ & 45169 (43.9) \\
\hline
\end{tabular}

identify patterns of frequent emergency department use, understanding contributing comorbidities and triggers, and providing early interventions may shorten the duration and morbidity of these episodes.
Importantly, our results indicate a growing prevalence of mental health issues and substance use among younger frequent users. For these subgroups, clinicians should consider initiating emergency department treatments when appropriate 
(e.g., in patients with opioid use disorder), and ensuring that timely access to community-based treatment and supports tailored to specific clinical and psychosocial needs are available from the emergency department.

Future studies should focus on further characterizing frequent users' heterogeneity and distinct subgroups. Differential mortality among subgroups has not been adequately explored. This is a required next step in identifying modifiable risk factors that could be mitigated to improve outcomes. In addition, studies should assess predictors of episodic and persistent frequent use of the emergency department over multiple years, to target these populations separately for interventions. Future qualitative work should engage health care providers and patients within specific subgroups to understand these frequent users' unmet needs and drivers of use, and to develop collaborative solutions. Studies should seek to understand increasing trends in mental health issues and substance use.

Finally, clinicians, hospitals and regions should pilot targeted approaches to address frequent users' heterogeneous needs, using settings other than the emergency department when possible. These directed interventions could include specific case management based on clinical and social needs, follow-up of mental health issues and substance use, medication reviews for those with polypharmacy (especially if there are multiple prescribers) and chronic disease management for older patients coordinated with a most responsible primary care provider.

\section{Limitations}

Our study has limitations inherent in analyses of data from large administrative databases. We relied on NACRS emergency department records to create our study cohort. The observed increase in emergency department visits partially reflects an increase in NACRS reporting institutions. ${ }^{30} \mathrm{We}$ mitigated this by examining visit increase in a subset of consistently reporting institutions. The National Ambulatory Care Reporting System disproportionately includes emergency departments in larger urban and suburban centres. Nonetheless, it is the most comprehensive provincial database of emergency department visits. By 2015/16, 29 BC emergency departments had contributed 1.57 million records, for a provincial coverage rate of $74 \% .{ }^{55}$ Although NACRS has a flag for scheduled emergency department revisits, flagging is not mandatory and is therefore coded unreliably. We therefore developed a clinically driven algorithm to identify presumed revisits for cellulitis treatment. Our algorithm is unvalidated; however, we explored all 48-hour repeat visits, and cellulitis was the only commonly appearing diagnosis.

We could not explore important variables (e.g., homelessness, employment, ethnicity, individual and family income) not captured in included databases. Although a graded analysis of frequent use would have strengthened our analysis, we chose to examine the top $10 \%$ of users to remain consistent with Canadian Institute for Health Information standards. ${ }^{38}$

Missing data were nominal for most variables; however, the NACRS discharge diagnosis was missing for $25.8 \%$ of frequent users and $26.5 \%$ of nonfrequent users. Although these proportions are high, we do not suspect a systematic difference between groups, as there is no clinical reason why data abstractors would be more or less likely to code an emergency department diagnosis for frequent users. Canadian Institute for Health Information quality assurance indicates that missing emergency department diagnoses is due to incomplete reporting. ${ }^{56}$ Discharge diagnosis was a conditional mandatory field for level 2 reporting facilities in BC during the study period (i.e., completion of either presenting problem or discharge diagnosis was required). ${ }^{57,58}$ To mitigate coding inconsistencies, we collapsed diagnosis information into ICD-10 chapters, as previously described. ${ }^{59,60}$ Finally, the 4-year study time frame precluded us from assessing whether the observed trends have been consistent in the longer term or have persisted since 2015/16.

\section{Conclusion}

Emergency department use by frequent users increased in $\mathrm{BC}$ between 2012/13 and 2015/16. These patients were heterogeneous, were high users of other health care services, had higher mortality than nonfrequent users and rarely remained frequent users over multiple years. Our results suggest a need for interventions that account for this heterogeneity and that address factors that may trigger frequent use episodes.

\section{References}

1. National health expenditure trends, 1975 to 2019. Ottawa: Canadian Institute for Health Information; 2019.

2. Hospital cost drivers technical report: What factors have determined hospital expenditure trends in Canada? Ottawa: Canadian Institute for Health Information; 2012.

3. Pan-Canadian forum on bigh users of bealth care: summary report. Ottawa: Canadian Institute for Health Information; 2014.

4. Wodchis WP, Austin PC, Henry DA. A 3-year study of high-cost users of health care. CMA7 2016;188:182-8.

5. LaCalle E, Rabin E. Frequent users of emergency departments: the myths, the data, and the policy implications. Ann Emerg Med 2010;56:42-8.

6. Emergency department visits in 2014-2015. Ottawa: Canadian Institute for Health Information. Available: https://secure.cihi.ca/free_products/NACRS_ ED_QuickStats_Infosheet_2014-15_ENweb.pdf (accessed 2020 Apr. 29).

7. Mitchell MS, León CLK, Byrne TH, et al. Cost of health care utilization among homeless frequent emergency department users. Psychol Serv 2017;14:193-202.

8. Korczak V, Shanthosh J, Jan S, et al. Costs and effects of interventions targeting frequent presenters to the emergency department: a systematic and narrative review. BMC Emerg Med 2019;19:83.

9. Ovens HJ, Chan BT. Heavy users of emergency services: a population-based review. CMA7 2001;165:1049-50.

10. Fuda KK, Immekus R. Frequent users of Massachusetts emergency departments: a statewide analysis. Ann Emerg Med 2006;48:9-16.

11. Hansagi H, Olsson M, Sjöberg S, et al. Frequent use of the hospital emergency department is indicative of high use of other health care services. Ann Emerg Med 2001;37:561-7.

12. Moe J, Kirkland S, Ospina MB, et al. Mortality, admission rates and outpatient use among frequent users of emergency departments: a systematic review. Emerg Med 7 2016;33:230-6.

13. Pines JM, Asplin BR, Kaji AH, et al. Frequent users of emergency department services: gaps in knowledge and a proposed research agenda. Acad Emerg Med 2011;18:e64-9.

14. Ruger JP, Richter CJ, Spitznagel EL, et al. Analysis of costs, length of stay, and utilization of emergency department services by frequent users: implications for health policy. Acad Emerg Med 2004;11:1311-7.

15. van Tiel S, Rood P, Bertoli-Avella A, et al. Systematic review of frequent users of emergency departments in non-US hospitals: state of the art. Eur 7 Emerg Med 2015;22:306-15.

16. Soril LJJ, Leggett LE, Lorenzetti DL, et al. Reducing frequent visits to the emergency department: a systematic review of interventions. PLoS One 2015; 10:e0123660.

17. Dufour I, Chouinard MC, Dubuc N, et al. Factors associated with frequent use of emergency-department services in a geriatric population: a systematic review. BMC Geriatr 2019;19:185. 
18. Moe J, Kirkland SW, Rawe E, et al. Effectiveness of interventions to decrease emergency department visits by adult frequent users: a systematic review. Acad Emerg Med 2017;24:40-52.

19. Althaus F, Paroz S, Hugli O, et al. Effectiveness of interventions targeting frequent users of emergency departments: a systematic review. Ann Emerg Med 2011;58:41-52.e42.

20. Chan BTB, Ovens HJ. Frequent users of emergency departments. Do they also use family physicians' services? Can Fam Physician 2002;48:1654-60.

21. Doupe MB, Palatnick W, Day S, et al. Frequent users of emergency departments: developing standard definitions and defining prominent risk factors. Ann Emerg Med 2012;60:24-32.

22. Kumar GS, Klein R. Effectiveness of case management strategies in reducing emergency department visits in frequent user patient populations: a systematic review. 7 Emerg Med 2013;44:717-29.

23. Lucas RH, Sanford SM. An analysis of frequent users of emergency care at an urban university hospital. Ann Emerg Med 1998;32:563-8.

24. Sandoval E, Smith S, Walter J, et al. A comparison of frequent and infrequent visitors to an urban emergency department. F Emerg Med 2010;38:115-21.

25. Zuckerman S, Shen YC. Characteristics of occasional and frequent emergency department users: Do insurance coverage and access to care matter? Med Care 2004:42:176-82.

26. Blank FSJ, Li H, Henneman PL, et al. A descriptive study of heavy emergency department users at an academic emergency department reveals heavy ED users have better access to care than average users. F Emerg Nurs 2005;31:139-44.

27. Palmer E, Leblanc-Duchin D, Murray J, et al. Emergency department use: Is frequent use associated with a lack of primary care provider? Can Fam Physician 2014;60:e223-9.

28. McCusker J, Verdon J. Do geriatric interventions reduce emergency department visits? A systematic review. 7 Gerontol A Biol Sci Med Sci 2006;61:53-62.

29. Hastings SN, Heflin MT. A systematic review of interventions to improve outcomes for elders discharged from the emergency department. Acad Emerg Med 2005; 12:978-86.

30. National Ambulatory Care Reporting System (NACRS). Vancouver: Population Data BC. Available: www.popdata.bc.ca/data/health/nacrs (accessed 2020 June 18).

31. Peterson S, Wickham M, Lavergne MR, et al. Methods to comprehensively identify emergency department visits using administrative data in British Columbia. Vancouver: UBC Centre for Health Services and Policy Research; 2020.

32. Canadian Institute for Health Information. Discharge Abstracts Database (hospital separations file) [data abstract]. Vancouver: Population Data BC; 2011, updated 2018. Available: www.popdata.bc.ca/data/health/dad (accessed 2020 Apr. 29).

33. British Columbia Ministry of Health. Medical Services Plan (MSP) payment information file [data abstract]. Vancouver: Population Data BC; 2011, updated 2018. Available: www.popdata.bc.ca/data/health/msp (accessed 2020 Apr. 29).

34. British Columbia Ministry of Health. PharmaNet [data abstract]. Version 2. Vancouver: Population Data BC; 2011, updated 2019. Available: www.popdata. bc.ca/data/health/PharmaNet (accessed 2020 Apr. 29).

35. BC Vital Statistics Agency. Vital statistics deaths [data extract]. Vancouver: Population Data BC; 2011, updated 2018. Available: www.popdata.bc.ca/data/ population (accessed 2020 Apr. 29).

36. Ark TK, Kesselring S, Hills B, et al. Population Data BC: supporting population data science in British Columbia. Int 7 Popul Data Sci 2020;4:1133.

37. Chamberlayne R, Green B, Barer ML, et al. Creating a population-based linked health database: a new resource for health services research. Can 7 Public Health 1998;89:270-3.

38. Dynamic cohort of complex, high system users: 2011-2015 - a CIHR-CIHI collaboration. Ottawa: Canadian Institute for Health Information; 2017. Available: https://cihr-irsc.gc.ca/e/50129.html (accessed 2020 Apr. 12).

39. Postal Code ${ }^{\mathrm{OM}}$ Conversion File (PCCF), reference guide. Ottawa: Statistics Canada; 2017, modified 2020 Nov. 19. Available: www150.statcan.gc.ca/n1/ pub/92-154-g/92-154-g2017001-eng.htm (accessed 2020 Apr. 12).

40. Population estimates. Victoria: British Columbia Ministry of Health. Available: www2.gov.bc.ca/gov/content/data/statistics/people-population-community/ population/population-estimates (accessed 2020 Apr. 12).

41. Canadian Triage and Acuity Scale. Available: http://ctas-phctas.ca/ (accessed 2020 Apr. 29).

42. Bullard MJ, Musgrave E, Warren D, et al. Revisions to the Canadian Emergency Department Triage and Acuity Scale (CTAS) guidelines 2016. C7EM 2017;19(Suppl 2):S18-27.

43. Grafstein E, Innes G, Westman J, et al. Inter-rater reliability of a computerized presenting-complaint-linked triage system in an urban emergency department. CFEM 2003;5:323-9.

44. Lee JY, Oh SH, Peck EH, et al. The validity of the Canadian Triage and Acuity Scale in predicting resource utilization and the need for immediate lifesaving interventions in elderly emergency department patients. Scand 7 Trauma Resusc Emerg Med 2011;19:68.

45. Dong SL, Bullard MJ, Meurer DP, et al. Predictive validity of a computerized emergency triage tool. Acad Emerg Med 2007;14:16-21.

46. Lavergne R, McGrail K, Peterson S. Defining and measuring full service family practice in BC, 1991-2006 [working paper]. Vancouver: UBC Centre for Health Services and Policy Research; 2013. Available: https://deslibris.ca/ID/239610 (accessed 2020 Apr. 29).
47. Lavergne MR, Peterson S, McKendry R, et al. Full-service family practice in British Clumbia: policy interventions and trends in practice, 1991-2010. Healthc Policy 2014;9:32-47.

48. International Statistical Classification of Diseases and Related Health Problems, 10th Revision. Geneva: World Health Organization; 2019. Available: https://icd. who.int/browse10/2019/en (accessed 2020 Apr. 29).

49. Schneeweiss S, Seeger JD, Maclure M, et al. Performance of comorbidity scores to control for confounding in epidemiologic studies using claims data. Am 7 Epidemiol 2001;154:854-64.

50. Pharmacologic-Therapeutic Classification AHFS. Bethesda (MD): American Hospital Formulary Service. Available: www.ahfsdruginformation.com/ahfs -pharmacologic-therapeutic-classification/ (accessed 2020 May 5).

51. Gill JM, Mainous AG 3rd, Nsereko M. The effect of continuity of care on emergency department use. Arch Fam Med 2000;9:333-8.

52. Ionescu-Ittu R, McCusker J, Ciampi A, et al. Continuity of primary care and emergency department utilization among elderly people. CMA7 2007;177:1362-8.

53. Doupe MB, Palatnick W, Day S, et al. Frequent users of emergency departments: developing standard definitions and defining prominent risk factors. Ann Emerg Med 2012;60:24-32.

54. Kerr T, Wood E, Grafstein E, et al. High rates of primary care and emergency department use among injection drug users in Vancouver. 7 Public Health (Oxf) 2005;27:62-6.

55. NACRS emergency department visits and length of stay by province/territory, 2016-2017. Ottawa: Canadian Institute for Health Information. Available: www.cihi.ca/en/nacrs-emergency-department-visits-and-length-of-stay -2016-2017 (accessed 2020 May 9).

56. Data quality documentation: National Ambulatory Care Reporting System. Current-year information 2019-2020. Ottawa: Canadian Institute for Health Information. Available: www.cihi.ca/sites/default/files/document/nacrs-data -quality-current-year-information-2019-2020-en.pdf (accessed 2020 May 9).

57. NACRS: frequently asked questions. Ottawa: Canadian Institute for Health Information; 2009, updated 2012. Available: https://silo.tips/download/nacrs -frequently-asked-questions (accessed 2020 Apr. 30).

58. NACRS data elements 2015-2016. Ottawa: Canadian Institute for Health information. Available: www.cihi.ca/sites/default/files/document/nacrs_data_ elements_2015_16_en.pdf (accessed 2020 Apr. 30).

59. Park S. Patient complexity in primary care: grouping systems with a special focus on validity and applications in primary care settings. Vancouver: Models and Access Atlas for Primary Care at Providence Health Care; 2016.

60. Quail JM, Lix LM, Osman BA, et al. Comparing comorbidity measures for predicting mortality and hospitalization in three population-based cohorts. BMC Health Serv Res 2011;11:146.

Affiliations: Departments of Emergency Medicine (Moe, O'Sullivan, Grafstein, Hohl) and Family Practice (McGregor), University of British Columbia; Department of Emergency Medicine (Moe, Hohl), Vancouver General Hospital, Vancouver, BC; ICES Central (Schull); Department of Medicine (Schull), University of Toronto, Toronto, Ont.; Department of Emergency Medicine (Dong, Holroyd), University of Alberta; Emergency Strategic Clinical Network (Holroyd), Alberta Health Services, Edmonton, Alta.; Patients for Patient Safety Canada (Trimble), Roberts Creek, BC; School of Population and Public Health (McGrail), University of British Columbia; Population Data BC (McGrail), Vancouver, BC

Contributors: Jessica Moe conceived of and designed the study, with input from all the other authors. Jessica Moe, Fiona O'Sullivan and Kimberlyn McGrail acquired and analyzed the data. Jessica Moe drafted the manuscript. All of the authors interpreted the data, revised the manuscript critically for important intellectual content, approved the final version to be published and agreed to be accountable for all aspects of the work.

Funding: This study received funding from the Vancouver Coastal Health Research Institute.

Data sharing: The data from this study are held in a secure research environment managed by Population Data BC (PopData BC). The data were provided to PopData BC by the British Columbia Ministry of Health under specific data-sharing agreements. Access may be granted to those who request it from the corresponding author.

Content licence: This is an Open Access article distributed in accordance with the terms of the Creative Commons Attribution (CC BY-NC-ND 4.0) licence, which permits use, distribution and reproduction in any medium, provided that the original publication is properly cited, the use is noncommercial (i.e., research or educational use), and no modifications or adaptations are made. See: https://creativecommons.org/licenses/by-nc-nd/4.0/.

Supplemental information: For reviewer comments and the original submission of this manuscript, please see www.cmajopen.ca/content/9/1/ E134/suppl/DC1. 